\title{
Reflection on Micro Class in Chinese Universities in "Internet plus" Era
}

\author{
Mingxiu Chen \\ School of Humanities \\ Northeast Normal University \\ Changchun, China
}

\author{
Qi Wang \\ Changchun University \\ Changchun, China
}

\begin{abstract}
This paper analyzes the real value of micro class through sorting out the deep reasons of micro class's generation and prevailing in foreign countries, and illustrates that the development of micro class in China is the inevitable choice for higher education in "Internet plus" era.
\end{abstract}

Keywords-“Internet plus" era; micro class; Chinese universities; reflection

\section{INTRODUCTION}

As the advanced institution of higher learning for imparting knowledge, universities shoulder the responsibilities of rendering students the professional knowledge, broad vision, personality development and further development of ability and potential. In the era of "Internet + " rapid development, students have increasingly more channels for information acquisition, such social communication software as MicroBlog, WeChat and Blog are popular in the campus. Therefore, the education in universities is required to keep pace with the times, to have the characteristics of diverse educational forms, education mode reform and education method innovation, so as to transform students' passive learning to active learning, and motivate their learning potential. Whether micro class is temporary, or the investible process of education development, and whether education can manage itself along in the era of "Internet +", we have to explain from the background of this "imported" product's generation and prevailing in foreign countries against the true features of micro class. The development and application of micro class video resources in foreign countries started with the implementation of governmental education policy as entry point, and gradually transit to the self-dependent innovation of academic institution and expert team from government investment, and drive the investment of public funds through radiation. The sharing management mechanism of micro class video database based on Wiki function finally finds out its way to develop to diversification and specialization in the future [1]. It can be seen that the final objective of micro class, whether it is government investment or social funding, is to help raise the teachers' teaching ability, and help students to improve their learning effect, so as to achieve effective learning.

\section{SOME KNOWLedGe ABOUT Micro Class VAlue}

Domestic scholars generally agree that the micro class has the characteristics of short, small and clear. Short refers to the length micro class which is generally 10 minutes; small refers to the size of micro class, which is conducive to mobile learning and online learning as it takes up little space; clear refers to the content of micro class video is concise and refining. Looking from the appearance, micro class is featured by short, small and clear, but if viewed from the deep level, the true value of micro class is learner-centered, to dig the learner's internal motivation to learn actively, and stimulate students' creative ability through the fragmented knowledge.

\section{A. The Premise Is Learner-centered}

Micro class enable the learners to learn selectively without regional restrictions, therefore, the class design must be required to be learner-centered, and develop the courses that the learners are willing to accept against learners' learning characteristics, learning habits, learning ability and learning purpose. The course is open as the option is in the hands of learners. In addition, there shall be both challenging and interesting in course design, theme selection and methods setting and video recording process. Learning is a process of constantly promoting, and the learner will be surprised and moved with thinking and achievement in the process.

\section{B. The Core Driver Is Students' Active Learning and Exploration}

Only the sustained and effective learning can eventually benefit the learners whether in traditional class or micro class, which undoubtedly requires a higher level for micro class. To realize continuous self-study without supervision and urge of the teachers, requires the micro class to be able to stimulate students' internal active learning potential essentially and develop their enthusiasm of learning, which is also the key points and difficulties of network course development, and also the real value of network course. Therefore, the research of learners' long-term learning driving force in micro class cannot be ignored.

\section{The Ultimate Root Lies in Fragmented Knowledge}

Whether the adding of several classes can form MOOC? The answer is no. The real value of micro class lies in it can make the important or difficult knowledge into a piece of knowledge, which is to be used on mobile terminal with the aid of multimedia technology in class or after class. Those pieces of knowledge are more attractive and complete 
compared to the traditional classroom teaching content, which are conducive to the students for them to better understand the knowledge in class, but also help students to review after class, thus to improve learning efficiency and effectiveness. MOOC is the network course opened to the public regarding high quality teaching resources. If we compare micro class as human's eye, then MOOC is the whole body. The true value of MOOC is to break the regional restrictions of education, to realize education fairness without boundaries.

\section{The purpose Is to Stimulate Creativity}

The starting point of micro class is to build a kind of relaxed and elegant atmosphere, to promote the right brain learning, improve learning efficiency and stimulate learners' creativity [2]. Micro course is not only the innovation of learning methods and learning content, but also the promotion of learning effect. Efficient learning not only means that students can acquire the required knowledge, but also means that the learners' creativity can be stimulated through learning. The inspiration of creativity will produce a series of innovation wisdom, and the innovation wisdom shall be applied to all aspects of the society, which will promote social progress.

\section{ESTRAINING FACTORS FACED BY DOMESTIC MICRO CLASS DEVELOPMENT}

Domestic study on micro classes began in 2013, which mainly focused on the following three points: the first is micro class design, development and evaluation in universities; the second is the current situation of micro classes research and related problem research in universities; the third is the specific application of micro class, which mainly is the research on application of micro class in a certain course, and the research focus still follows and intimates the research method of traditional class, which is lack of innovation. Domestic micro class research is still in the exploratory stage, and many of the front-line teachers in colleges and the relevant department have no clear purpose toward micro class design, development and application. Many of the micro class designs are used for satisfying micro class competition, or for study and communication between teachers. There is no clear understanding of the reasons to design and develop micro class, the methods to use micro class as well as the specific construction and application of micro class. The reason mainly comes from the following three aspects.

\section{A. Emotional Confusion and Struggle of Front-line Teachers}

The emotional confusion and struggle of front-line teachers mainly comes from three aspects. The first is their own inertia, because teachers need to invest a great deal of time and effort from design to molding of micro class, and the biggest resistance is that they are not familiar with the micro class production software, for example, the common screen record software Camtasia Studio. Teachers are familiar with the commonly used Office software, and there will be inner resistance for them to learn to use new software. The second is the resistance to micro class that has been recorded by others. A teacher with self-esteem will be reluctant to recommend students to watch other teachers' micro class that is better than his/her own in class or after class, because he/she will feel his/her prestige will be affected. And these teachers learn from other's micro class to improve their own teaching level. The third is the fear of micro class, worrying about whether or not micro class will replace teachers. The teachers record their knowledge accumulation with micro class, and can be reused, or the existing micro class of other universities on the internet is better than their own, if micro class sharing is realized, they worry about whether or not their jobs will be threatened. It can be seen from the above three aspects that front line teachers have not emotionally accepted micro class, and have weak subjective initiative toward production and application of micro class.

\section{B. Micro Class Has Not Been Practically Used for Teaching}

As an imported product, micro class is widely used in foreign countries, having been integrated into the daily teaching with remarkable teaching effect. However, most of the construction and application of micro class in our country stay on the micro class competition, and the micro class has not been practically used for teaching, and lack of management and research on micro class practice and the application process. The key problems such as how to guide the orderly development of micro class with teaching demand, how to deal with the problems existing in the development process of domestic micro class, how do the universities keep pace with the times in the era of "Internet $+"$ and carry out the micro class construction, strengthen the practical application, as well as deepen the reform of higher education, need to be focused on and solved. The development of micro class in foreign countries is indispensable to sharing and public interest. However, the starting point of domestic micro class is utilitarian teaching competition. Domestic universities encourage teachers to carry out micro class recording one after another for the sake of comparison, awards, ratings, raising awareness. Teachers choose to fight alone, thus the micro class can only be regarded as the works for competition, such micro class is often costly without effect, let alone to be beneficial to the students. It is expected that this is just an "introduction" for micro class to change higher education, but not the end of micro class.

\section{Strong Inertia of Traditional Teaching Mode}

The alienation of education is to extend the production mode of industrial assembly line into the education system and learning style of school's talent cultivation. The education "assembly line" of mechanical infusion and standardized tests has "manufactured" numerous young students full of vitality into the uniform "standard" parts and has killed their creativity and vivid personality [3]. The "assembly lined" education mode which is deeply rooted has been used for a long time in the educational circles in our country, and it is the same with the students, the teachers as well as colleges and universities. The disadvantages of such education have appeared gradually, as the lack of creativity and innovation ability is the direct consequence caused by the inertia of traditional teaching mode. However, the powerful inertia is inseparable from the system, policies and ideology, social psychological used for modern society's talent selection, cultivation and appointment [3]. Therefore, the factors hindering education progress are complex. 


\section{MicRo ClasS DEVELOPMENT-THE ONLY WAY OF CHINA's HIGHER EDUCATION IN THE ERA OF "INTERNET + "}

There is a very famous education philosophy, namely, the Question of Jobs, "over the past 20 years, IT industry has changed almost all the areas relating to human, why its impact on education does is surprisingly little?"[3] Jobs left this question to us to answer, and the times is walking from IT to DT, thus "Internet + " is generated. "Internet + " creates a kind of new and healthy living or studying way via the influence of Internet, and bring people the behavior change through Internet. However, currently, it can only be regarded as "+ Internet" in higher education, because we just add some things from the Internet into our class. For example, we add video, media and music into our class, and this can only be regarded as applying modern education technology application to the classroom. "Internet + Education" happen to coincide with the university education reform goal, and micro class is the effective exploration of "Internet + Education". Micro class development is the only path of China's higher education in the era of "Internet $+"$. Because the education against learners is imperative, and education reform is urgently needed. Although small class is the direction and trend of education in the future, it can't completely replace the classroom teaching. However, the implementation of small class will increase the effect of classroom teaching. In the future, network course and classroom teaching will develop in parallel.

\section{A. Stimulate Teachers' Inherent Professional Spirit of "Imparting Knowledge and Explaining Puzzle"}

It is the key problem we need to solve first to relieve the front line teachers' emotional confusion and struggle, arouse teachers' inherent professional spirit of "imparting knowledge and explaining puzzle", and improve the teachers' subjective initiative toward micro class production and application. As a new thing, micro class needs more supports from multiple aspects at the initial development stage. The encouragement and recognition shall be provided in term of policy, for example, give more support to workload calculation, selection of the advanced ones and title assessment, so as to prompt the teachers to record and use micro class more actively.

The settlement of this problem will be conducive to the recording of micro class, and to the micro class's entering into the classroom, so that it may actually be used in the practice. And the strong inertia of traditional teaching mode will collapse slowly to form a new teaching mode. In addition, while researching teaching methods, what is more important is to research the students' methods to study it. The traditional theory of behaviorism uses stimulus - reflection, which will be abandoned slowly, and the newly constructed theory should play the dominant role.

\section{B. Pay Attention to the Teaching Design of Micro Class}

Micro class is not only a teaching method reform, but is a complex and systematic work integrating the conception, design, practice and application of "Internet $+"$. Micro class is a learning mode of network courses by the learners under the demand of self study goal through network. It can be seen that the feature of micro class is the vivid video broadcast and not the simple words or pictures, and it is an intuitive and emotional micro video. Therefore, we should make full use of the advantage of this course, to design the short, informative and widely used micro video with the characteristics of outstanding theme, real situation, diversified resources, vivid cases and enthusiastic discussions.

If the use of the multimedia is the first leap of classroom teaching, then the Internet teaching resources, such as micro class, are the second leap of not only the classroom teaching but also the history of education. Along with the continuous growth of the Internet teaching resources, such as micro class, the popularity of education scope will break through the geographical constraints of campus, to meet different people's thirst for education, realize fair education and resource sharing, so as to really realize the public education. The micro class construction and development in colleges and universities in the era of "Internet +", will help to promote higher education's contribution to the society, so that it can complete its social mission and historical mission better.

\section{REFERENCES}

[1] Wu Bingiian. Foreign Micro Class Resources Development and Application Case Analysis [J]. Information Technology Education in Primary and Middle Schools, 2013,(4):23-26.

[2] Sun Yuesheng. Question and Reflection on Micro Class Fever in Primary and Middle Schools [J]. Contemporary Educational Science,2015,(4):42-46.

[3] Sang Xinmin, Li Shuhua, Xieyangbin. Cultural Strategy Interpretation of "Question of Jobs"---Deep Reflection on New Trend of Online Courses [J]. Open Education Research, 2013, (3):30-41. 